\title{
Demócratas, mediocres y técnicos Las tensiones del futuro universitario en el Perú
}

\begin{abstract}
RESUMEN
Este artículo trata de la relación entre el abandono estatal, la mediocridad, la razón democrática y la razón tecnocrática en la universidad peruana en el último siglo. La secuencia se plantea como la lógica y el conflicto entre distintos discursos que buscan darle un rumbo a la institución universitaria en el proceso de reforma de la misma que empieza con la impronta del movimiento universitario de Córdoba en 1918 y no termina hasta el presente. Resalta la formación de una razón democrática y su devenir en los distintos procesos de crisis y cambio de la universidad como el discurso que le puede dar futuro a la producción de conocimientos en el Perú.
\end{abstract}

Palabras Clave: universidad; Estado; democracia; mediocridad; razón; tecnocracia

\section{Democrats, mediocre and technicians. The tensions of the university future in Peru}

\begin{abstract}
The current article explains the relatinonship between the lack of State support, faculty mediocrity, democratic reason and technochratic reason in the Peruvian university in the last century. It presents the sequence of logic and conflict between the different discourses in the process of reform of higher education starting with the university movement in Córdoba, Argentina in 1918 to the present times. The article highlights the formation of democratic reason in the different moments of crisis and change in the university and states that this kind of reason is the possibility of giving a future to the production of knowledge in Perú.
\end{abstract}

KEYwORDs: university; State; democracy; mediocrity; reason; technocracy.

$1 \quad$ El argumento central de este texto fue presentado como conferencia en la Universidad Nacional San Agustín de Arequipa, el 4 de julio de 2015; en la Pontificia Universidad Católica del Perú, el 27 de octubre de 2015; y en la Universidad Nacional San Antonio Abad del Cusco, el 11 de diciembre de 2015. Agradezco a Francesca Denegri por la idea inicial, a Esperanza Medina y David Ugarte por las invitaciones a hablar en sus claustros y a César Aguilar y Gerardo Rénique por sus agudas observaciones a distintas versiones de este texto. 


\section{El abandono estatal y la mediocridad}

E n mi encuentro con San Marcos, hace ya más de cuarenta años, traía una visión romántica de la universidad a la cual me acercaba, con la convicción juvenil de poder empezar a realizar allí la vocación intelectual y política que comenzaba a aflorar. Este encuentro fue catastrófico y apasionado a la vez. La falta total de recursos, mucho más aguda de la que sufrimos hoy, que daba cuenta del abandono del Estado de la universidad pública al constatar aquel que esta se había convertido en un centro irrecuperable de rebeldía, se hacía patente a cada paso. Ese abandono, que años más tarde llamaría incuria, en el sentido de indiferencia y desprecio que la palabra tiene, fue mi primera certeza sobre la universidad y su relación con el mundo circundante.

Eran los primeros años de la década de 1970, cuando los profesores relacionados con la vieja oligarquía habían abandonado el claustro o habían sido expulsados por el movimiento universitario y las nuevas generaciones, más enfocadas en la política, distaban de llenar el vacío académico que ellos habían dejado. A este vacío se sumaba la escasez radical de recursos que impedía atraer nuevos cuadros y proyectaba una imagen de pobreza que persiste hasta el día de hoy. Como en otros ámbitos de la vida peruana, era el resultado del triunfo a medias del movimiento antioligárquico en su versión universitaria: la derrota interna de quienes impedían la democratización de la universidad y, al mismo tiempo, la incapacidad de conseguir recursos y producir un reemplazo que construyera una universidad diferente. Era, quizás, un episodio más de ese período en el siglo xx en el que la democratización promovida por los actores sociales no promovía democracia.

Frente al abandono del Estado, el radicalismo izquierdista, que era la respuesta de la juventud universitaria de la época, parecía lo más natural. Con el tiempo, sin embargo, haría la disección de ese radicalismo que me embargó en su momento. No solo había retórica revolucionaria sino también pragmatismo cortoplacista. Los llamados a la revolución que llevaron a muchos jóvenes de los ańos setentas a comprometerse con las transformación del país y conformar una generación de cambio que hasta hoy continúa con su aliento transformador, también tuvo su contraparte más pedestre. En Los jóvenes rojos de San $\operatorname{Marcos}$ (1990) daría cuenta de la consigna «ser profesional como sea", que nos permitía a los radicales de la época movilizar a las masas estudiantiles en aras del facilismo académico. Carlos Iván Degregori (1990), en la revisión de la currícula de diversos programas de ciencias sociales en las universidades públicas haría una cosa similar. Más tarde aún, y pasadas las épocas del radicalismo universitario que en algún momento nos parecieron heroicas, hice la conexión entre abandono estatal, radicalismo y pragmatismo, señalando que lo que habían engendrado en la universidad era la mediocridad.

Cuando publiqué La segunda reforma universitaria (2005) señalé, por primera vez con cierto detalle, la relación que acabo de exponer. Hoy quiero resaltar que del abandono estatal de la universidad es relativamente fácil hablar, pero que mencionar su producto - la mediocridad — sigue siendo casi vedado, pues se trata de referirse a un importante sector de la docencia universitaria que entró a la misma en las décadas de 1970 y 1980, muchas veces sin tomar en cuenta sus méritos académicos, sino más bien atendiendo a sus relaciones políticas. Sin embargo, ésta última es la que ha permeado la universidad en las décadas recientes, tanto la pública en la deriva que planteara líneas arriba, como la más nueva, la privada con fines de lucro, en los últimos veinte años. Para vencer el cáncer de la mediocridad, proponía y propongo completar la razón democrática que había levantado la primera reforma universitaria empezada en Córdoba en 1918 con una segunda reforma que sumara a la democracia la calidad de la educación universitaria.

Pero, hay que decir también, que quienes nos ocupamos de la universidad desde una perspectiva democrática, no tomamos en cuenta, que hubiera una respuesta "desde arriba» a la mediocridad, desde aquel Estado indolente que el último medio siglo había abandonado la universidad. Ya no solo han sido las facilidades que se dan para desarrollar el negocio universitario a cualquier costo a partir de la dictadura de Alberto Fujimori y Vladimiro Montesinos, sino también la gestación de un proyecto tecnocrático que busca extender sus criterios maximizadores a universidadaes públicas y privadas vía la denominada Superintendencia Nacional de Educación Superior Universitaria (Sunedu). 
Tenemos entonces una reacción del Estado al abandono anterior en dos pasos. Uno primero con la "liberación» del mercado en la educación universitaria por el Decreto Legislativo (DL) 882, que crea las universidades privadas de manejo corporativo $y$ con fines de lucro, y otro segundo que busca el control tecnocrático de todas las universidades, públicas y privadas, a través de la Sunedu. En ambos se busca promover criterios privatizadores, primero a través de la «mano invisible» del mercado, que resulta caótica con la creación de decenas de universidades sin ningún control, y, segundo, por el camino, esta vez sí del control de la oferta y la gestión universitaria que atiende a criterios cuya definición democrática es inexistente y soslaya la indispensable autonomía universitaria. Ya no es el Estado oligárquico de la exclusión abierta, hoy se trata del Estado neoliberal que mide a los actores en función de la oferta y la demanda de productos y servicios, menospreciando el peso de la esfera pública en la educación universitaria.

\section{La razón democrática: sus inicios}

Por razón democrática, recuperando el término razón tan caro a la modernidad, me refiero a la manera de organizar y gestionar la universidad, democráticamente - en cuanto a acceso, gobierno, enseñanza e investigación - porque creo que esta es la forma de que ella cumpla de la mejor manera con su función central: la creación de conocimientos. La relación entre democracia y universidad es un parteaguas en torno a la misma. Los que creemos en la universidad como una institución democrática solemos tener una convicción democrática sobre la organización de la sociedad, mientras que aquellos que tienen convicciones autoritarias de diverso grado sobre la organización social las reflejan también en la universidad. No es casualidad, como veremos más adelante, que el DL 882 haya sido dado durante la dictadura de Fujimori y Montesinos.

Argumenté en «La segunda reforma universitaria» que la razón democrática de la primera reforma, había atendido al acceso y al gobierno de la Universidad, a la gratuidad de la enseñanza, así como a la pluralidad de los contenidos que se imparten (Del Mazo 1967), pero que se había agotado en la derrota del dominio oligárquico al no poder estable- cer un nuevo modelo universitario en el Perú ${ }^{2}$. De esta lucha son hijos los intentos reformistas de 1919, 1931, 1946 y 1961; hasta coronarse - luego de los decretos leyes autoritarios de 1969 y 1972 - con lo que denominé "el Córdoba tardío» que Luis Alberto Sánchez plasma en la ley de 1983. Los cuatro primeros son de contenido claramente antioligárquico y el cuarto produce la disidencia conservadora en la Facultad de Medicina de San Fernando que rompe San Marcos para ir a fundar la Universidad Peruana Cayetano Heredia, justamente por estar en desacuerdo con el cogobierno universitario de estudiantes y profesores. En todos ellos se busca implementar las banderas de la primera reforma - acceso y gobierno democráticos - pero se deja de lado la calidad de la enseñanza y la investigación. Esta es una reflexión que ya está en una conferencia de Augusto Salazar Bondy (1957) en la Facultad de Educación de San Marcos y que hoy retomo en mi argumentación.

Los intentos autoritarios de 1969 y 1972, durante el gobierno militar reformista de Juan Velasco Alvarado, fueron intentos de terminar con el abandono estatal que había empezado con la crisis del dominio oligárquico de la universidad. Sin embargo, no trascendieron a sus autores y se ahogaron en la resistencia de un movimiento universitario que seguía viendo a los militares como el "perro guardián" de la oligarquía y, por lo tanto, como sus enemigos naturales. Empero, es importante precisar que estos intentos estaban presididos por la preocupación de conectar a la universidad con el país y que su perfil tecnocrático apuntaba, dentro de un criterio general de «reforma de la educación», a planificar el desarrollo universitario en función del desarrollo nacional. A pesar de su corta vida, dejaron la idea de «sistema universitario" y la necesidad de una instancia de regulación del mismo. Pero sistema e instancia regulatoria serían olvidadas con la vuelta de la Asamblea Nacional de Rectores en la ley de 1983. Habría que esperar el debate universitario posterior, de principios de este siglo XXI, para retomar aquellas valiosas ideas

2 No está de más recordar el antecedente al propio movimiento reformista de Córdoba, que ocurre en la Universidad Nacional San Antonio Abad del Cusco entre 1907 y 1909, liderado entre otros por Demetrio Corazao y José Gabriel Cossio. El movimiento cusqueño levanta banderas similares a las de Córdoba y motiva la reforma de la universidad con la llegada del rector Alberto Giesecke en 1910. 
que aunque distorsionadas asoman en la ley actual, la 30220 .

Permítaseme una digresión en esta línea de tiempo. En las banderas de la primera reforma hay una cuestión que le da base material a la democracia, esta es la gratuidad de la enseñanza. El expediente de la democracia es la gratuidad. Me refiero a las públicas. La universidad que expresa a la nación solo puede ser gratuita porque es para todos. Y la gratuidad cumple dos funciones: integra a los que vienen de diversos orígenes sociales por ello es hogar de la nación y permite, a los que tienen menos, acceder a la universidad. La universidad gratuita, donde se supone que podrían estar todos busca la democracia y al revés, la democracia promueve la gratuidad. Esta es una conquista central, junto con la escuela pública, también gratuita, del precario Estado de bienestar latinoamericano ${ }^{3}$ que hoy masivamente se pretende desmontar. La sostenibilidad en el tiempo de esta universidad está dada por el compromiso del país con el conocimiento. Si se cuestiona una, la gratuidad, se cuestiona el compromiso con el conocimiento.

En el Perú, la situación es más grave que en otras partes de América Latina porque el soporte institucional de la gratuidad es más precario. Esta fue una conquista que se consiguió en el momento de crisis de la dominación oligárquica y que se ha hecho cada vez más difícil de mantener por la masificación universitaria, ocurrida a partir de la década de 1960. A esta precariedad permanente de las instituciones que garantizan derechos, de los intentos de formar un Estado democrático al fin y

cabo, se suma la ofensiva neoliberal que proclama la eliminación de los derechos, especialmente de los derechos sociales. La gratuidad constituye para esta ofensiva neoliberal el portaestandarte que hay que destruir, porque encarna la responsbilidad del Estado por el conjunto de la población, una responsabilidad por un colectivo social, en un tema tan delicado como la educación universitaria.

3 El símil, salvando distancias, del Estado de bienestar europeo en América Latina es el Estado nacional-popular, también denominado erróneamente como populista. Es el Estado que garantiza derechos, especialmente derechos sociales, entre ellos la educación gratuita. En el caso peruano, nunca hemos llegado a tener una estructura estatal que pueda denominarse así, salvo los intentos ocurridos entre 1968 y 1975 por el gobierno militar reformista encabezado por Juan Velasco Alvarado.
Ello no quita, sin embargo, que la gratuidad sea un tema altamente controvertido. Recuerdo a algunos colegas y amigos que en el debate sobre la reforma decían que «el hijo del emolientero no puede pagar lo mismo que el hijo del banquero». Sin embargo, la función de la gratuidad no es solo económica, sino también social. Compartir el mismo servicio público, en este caso de educación superior universitaria, es una experiencia fundamental para la construcción de la identidad nacional, de profesionales e intelectuales comprometidos con el desarrollo del país. Es más, si se trata del goce de derechos fundamentales en el ámbito público como es el caso de la universidad.

De ahí la diferencia de fondo que nos separa de las universidades privadas y, peor aún, de las privadas con dueño que tienen fines de lucro. En el espacio que genere la universidad pública y gratuita es posible que se puedan generar las condiciones para producir desinteresadamente conocimientos. Mientras que en los espacios universitarios generados por intereses privados muy difícilmente se va a producir esta operación fundamental, ya que la institución surge por intereses particulares y esto genera una situación contraria, en la que el interés es la ganancia de dinero en el corto plazo y no la libre producción de conocimientos.

Sigo entonces. La referencia a un Córdoba tardío para calificar la ley de 1983 es un préstamo abusivo de la arqueología que surge de mis conversaciones con Juan Abugattás, quien desafortunadamente ya no está entre nosotros. El me repetía que la ley de 1983 ya era caduca en el momento en que se promulga porque el modelo de gestión del conocimiento que plantea estaba pasado de moda. El énfasis en los esquemas organizativos del pasado, en un concepto autárquico en la autonomía y en la protección de los intereses creados de los distintos estamentos la hacían inviable. Lo primero lo observamos en el lugar que ocupan las facultades en esa ley, concebidas como compartimentos estancos y en la práctica autónomos, de allí que San Marcos tuviera que crear las Áreas Académicas e inscribirlas en su Estatuto en 2016 para promover la interdisciplinariedad. Pero también en el concepto de autonomía mismo, concebida en su exageración como autarquía que ha llevado al polo opuesto: la malhadada Sunedu. 
Sin embargo, como resultado de estos intentos reformistas, anteriores a la década de 1990, se instalan gobiernos democráticos en las universidades públicas y buena parte de las privadas existentes. Empero, sobre todo en las públicas de la época, carentes de preocupación por el desarrollo del conocimiento. Ello lleva a que, poco a poco, la universidad, principalmente la pública, sea copada por la mediocridad. En síntesis, dije, democracia sin calidad conduce a la mediocridad. Pero como me señala un amigo, quizás no había otra posibilidad. La oligarquía se ayudaba con las dictaduras militares y estas mataban a los estudiantes. Quizás no eran tiempos para la calidad.

\section{La razón democrática y la privatización}

En los últimos quince años se han dado avances sustantivos en el desarrollo de la razón democrática en la universidad producto de una preocupación mayor en el Perú sobre la educación, el movimiento universitario que reclama un cambio y una maduración de las ideas sobre reforma. Se han hecho diagnósticos y se han elaborado proyectos (diagnósticos en el 2002 y en el 2006, proyectos en el 2002 que no se llega a presentar y en el 2005, 2009 y 2013 que sí tienen trámite parlamentario). Todo esto finalmente ha desembocado en la aprobación de una nueva ley universitaria (2014) que busca juntar democracia y calidad. Todo, además, como producto del más vasto debate (2002-2014) sobre la universidad peruana que se recuerde - cerca de 40 reuniones en universidades públicas y privadas en todo el país- y los tres proyectos ya seńalados presentados al Congreso de la República, el último de los cuales se convierte en la Ley 30220 del 2014. Por ello vale decir que estamos ante una de las leyes universitarias más discutidas de nuestra historia.

Decir esto es importante, porque estamos acostumbrados a reclamar contra cualquier ley y señalar que no se ha discutido suficientemente. No ha sido el caso de esta, por más que no estoy de acuerdo en todo lo que contiene.

Pero el desarrollo de la razón democrática en la universidad no se da solo en contradicción con la mediocridad. La erupción de la razón democrática en los últimos años es una reacción también a la arremetida del neoliberalismo en la Universidad. A raíz de la aprobación del DL 882 por la dictadura de Fujimori y Montesinos en 1997, se inicia una ola privatizadora que no termina hasta hoy. La privatización significa la ruptura de los dos principios que hasta ese momento habían regido a la universidad peruana: la universidad sin fines de lucro y el gobierno democrático de la comunidad universitaria, que en las públicas supone la gratuidad. A partir del DL 882 se permiten el lucro y el gobierno corporativo, es decir la dictadura de los dueños. Es importante remarcar cómo ambas ideas se impusieron sin debate y por presión de quienes querían convertir, y en buena medida lo han logrado, a la universidad en un lucrativo negocio.

La arremetida neoliberal no es coincidencia ni tiene solo que ver con los tiempos que la favorecen. En la universidad expresa también la incapacidad de la democracia para producir calidad y enfrentar de esta manera al neoliberalismo. Por el contrario, la democracia se ha deteriorado y en el proceso ha producido manipulación y asambleísmo, lo que ha acentuado la mediocridad. Sin embargo, la arremetida neoliberal no ha generado el fenómeno opuesto, sino que nos ha traído más mediocridad, esta vez enmascarada por la búsqueda del dinero fácil, y el surgimiento de la razón tecnocrática.

Entre las que buscan el dinero fácil tenemos las universidades "chicha», la abrumadora mayoría de las llamadas "universidades con dueño" que adhieren a los dos principios del DL 882: hacer plata y establecer la dictadura de sus promotores, es decir sus dueños. Aproximadamente 70 de las 142 vigentes. Son las universidades, en la mayoría de los casos, de «tiza y pizarra» por las carreras baratas que ofrecen, sin mayor calidad y a clientelas masivas. Entre las que levantan la razón tecnocrática tenemos también a las universidades con dueńo, pero que al gobierno corporativo agregan la voluntad de constituirse «sin fines de lucro». Las primeras heredan la enfermedad de las universidades públicas, es decir, la mediocridad. En estas se juntan la ignorancia con la plata en una mezcla muy similar a la que se da en los ámbitos de la economía informal y hasta delictiva en el país. En las segundas se desarrolla la razón tecnocrática, el nuevo principio educativo, no solo universitario, que busca asentarse en el Perú.

Sin embargo, creo que la mediocridad ha sido el mayor mal a combatir en las universidades, tanto en las públicas como en las privadas, pero que su papel 
está en proceso de transformación. Me refiero a la mediocridad producto de la democracia sin calidad y a la mediocridad producto de las universidades chicha, que solo aspiran al negocio rápido. La ley universitaria vigente se ha hecho con este objetivo: combatir la mediocridad. Esta ha convertido a la democracia en prebenda. Los rectores se han estado eligiendo en distintas asambleas universitarias en base al voto comprado de algún sector estudiantil y también docente. El escándalo universitario ha llevado a la nueva ley. Podríamos estar viviendo, ojalá, el debilitamiento de la mediocridad en las universidades públicas. Queda, por supuesto, el cáncer de las privadas mediocres, capaces de cualquier cosa por sobrevivir.

Pero digo que la mediocridad está en proceso de transformación porque busca aliarse para sobrevivir con quien podría parecer su opuesto: la tecnocracia neoliberal. El escenario podría ser el proceso de licenciamiento, en el cual funcionarios inexpertos privilegian los números y las dimensiones y prestan poca atención a la calidad de las instituciones. La privatización abre así un nueva escenario de disputa por la universidad con rivales poderosos y perversos con los que no hubiéramos sońado treinta años atrás.

\section{Razón democrática versus razón tecnocrática}

La razón democrática tiene así en el horizonte a un nuevo adversario que puede convertirse en su enemigo: la razón tecnocrática. Definida la primera, señalo que razón tecnocrática refiere a una organización supuestamente eficiente de la institución universitaria que cumple con los objetivos trazados en función de los requerimientos del mercado, tal como se entiende éste en los tiempos de hegemonía neoliberal. Ello se da a partir de una supuesta naturalización de la neutralidad del conocimiento que sería la herramienta para la formación profesional y, si cabe, para alguna investigación.

Como dijimos, la razón tecnocrática actual tiene sus antecedentes en el impulso a universidades como la Universidad Nacional de Ingeniería (UNI) y la Universidad Nacional Agraria La Molina (UNA) a mediados del siglo xx. Asimismo, en el afán del gobierno militar de Velasco por ligar la universidad con el desarrollo nacional. En ambos casos fueron es- fuerzos postreros del período de democratización casi sin democracia, que tuvo la ilusión en los artefactos como un camino para promover la transformación del Perú oligárquico. Quizás el mejor ejemplo de estos esfuerzos fue el primer Fernando Belaunde Terry, arquitecto eminente y profesor de la UNI, cuyo programa político se asentaba en el mito de la construcción material de infraestructura.

Pero este era un afán tecnocrático de otro tipo que el actual, se trataba, supuestamente, de poner el conocimiento técnico al servicio del desarrollo del país, quizás del utópico desarrollo de un capitalismo nacional, que levantaba la posibilidad de entes colectivos como la comunidad, el pueblo o la nación que fueran los sujetos beneficiarios de los cambios. Distinto, repito, al capitalismo neoliberal de la actualidad cuyo afán tecnocrático está dirigido no al colectivo sino al individuo. Se trata de crear una oferta universitaria que esté al servicio de las necesidades del mercado, haciendo que ello sirva, a su vez, a la realización individual de la persona. Curiosamente, tanto en los antecedentes como en la actualidad, el afán tecnocrático neglige la democracia, presta relativa, si no poca, atención al régimen democrático a nivel nacional y casi ninguna atención a la democracia universitaria, a la que ve más como un lastre ligado a la mediocridad que como un camino para el futuro.

En esta disputa entre democracia y tecnocracia es fundamental dilucidar el contenido del concepto de calidad. Hace quince años, en una reunión mundial de la UNESCO sobre educación, cuyo lema fue «educación para todos», se definían los criterios para determinar qué era calidad educativa y se señalaban, en apretada síntesis, dos: el desarrollo de la capacidad cognitiva del estudiante y la identidad con su entorno. Ambos, además, debían ser logrados por la vía de la participación de la comunidad educativa. En resumen, la razón democrática. Pero con el neoliberalismo también se potencia una visión sesgada de lo que es calidad educativa. No el criterio integral presentado por la Unesco, sino nada más uno de sus aspectos: el desarrollo de la capacidad cognitiva. Se hace esto, además, negando la participación de la comunidad. Por eso la afición por los números, las evaluaciones y los ránkings, fuera de los cuales la humanidad no existe. Y no es que esté en desacuerdo con las evaluciones y los ránkings, aunque 
allí no empieza ni termina la universidad. Nosotros somos antiguos como institución en este mundo y a la vez modernos. Mil años dicen que tiene la institución desde sus escarceos en La Sorbona, por ello podemos juntar, si damos la talla, pasado, presente $\mathrm{y}$ futuro.

Continúo entonces. La razón tecnocrática se ha infiltrado en la nueva ley universitaria, pero no en la insistencia de la calidad como dicen los mediocres, no; sino al haber desvirtuado el gobierno del sistema universitario con la Sunedu. Lo que se planteó inicialmente fue un Consejo Nacional Universitario elegido por los profesores principales ordinarios y doctores de todas las universidades, no un ente ajeno manejado por el Ministerio de Educación. La discrepancia fue y es de fondo. Regulación entre pares o regulación desde arriba. La razón democrática plantea lo primero y la razón tecnocrática lo segundo. Si la regulación es desde arriba, y agrego, desde afuera, se afecta una condición fundamental para el desarrollo de una universidad que conjugue democracia y calidad: la autonomía. Es verdad que la autonomía está desprestigiada por los abusos que ha hecho de la misma el largo dominio de la mediocridad en la universidad peruana, siendo el mejor ejemplo de ello la fenecida Asamblea Nacional de Rectores ${ }^{4}$. Sin embargo, el que la autonomía se confundiera con autarquía y se usara para fines no muy santos, no condena a la autonomía como tal. Esta nació para hacer posible la universidad moderna en América Latina, siendo una herramienta para oponerse en una primera época a la injerencia del poder oligárquico y parece que ahora deberá renovarse para enfrentar al poder neoliberal. La autonomía es la que permite la democracia y la libertad de cátedra, sin las cuales el camino de la reforma universitaria es imposible

Pero hay más, al profundizarse el ánimo tecnocrático con la creación del Sunedu — que mediocremente nos habla se «estándares mínimos» y no de

4 La Asamblea Nacional de Rectores era un organismo de coordinación de las universidades peruanas conformado por los rectores de las mismas que dura hasta la dación de la ley universitaria 30220 en 2014. Si bien no era un organismo regulador asumió muy débilmente algunas funciones de tal. Sin embargo, su actividad fundamental fue la defensa del poder corporativo de los rectores y el poner en funcionamiento, en coordinación con el Congreso de la República, un mecanismo de autorización de nuevas universidades que creó más de cien nuevas casas de estudio superiores en aproximadamente quince ańos, sin velar por la necesidad y/o calidad de las mismas. excelencia académica - se pone en peligro la jerarquización de los saberes. Si la universidad tiene como tarea fundamental el desarrollo del conocimiento, una mala jerarquización del mismo lleva a su desnaturalización institucional. El tecnócrata, sujeto en nuestro país, en la abrumadora mayoría de los casos, a los intereses privados, va a entender el desarrollo del conocimiento como aquel aplicado para la fabricación de alguna mercancía, dejando de lado la investigación básica y la promoción de las artes, las humanidades y las ciencias sociales. Ya sucede con el Consejo Nacional de Ciencia y Tecnología del Perú (Concytec) y las ayudas sesgadas que da a posgrados y a la investigación, sucede también con ese programa denominado Beca 18, que le hace paralelismo a las universidades públicas y al que los tecnócratas neoliberales le dedican aproximadamente 900 millones de soles, casi un tercio del presupuesto del Tesoro que le dan a las públicas (Pronabec 2016).

Esta infiltración de la razón tecnocrática en la nueva ley universitaria apropiándose del organismo regulador, la ha llevado a una operación mayor, principalmente de carácter político y mediático, que tiene como objetivo hegemonizar el debate de las ideas sobre la educación universitaria. Sus voceros, empezando por el ex ministro Jaime Saavedra, señalan que lo que está en curso en el Perú es una «reforma universitaria». Esto tiene, antes que nada, una connotación histórica y política de proporciones, porque reforma universitaria refiere al movimiento de reforma que se iniciara en Córdoba, Argentina en 1918 y que, como señalamos líneas arriba, ha tenido múltiples repercusiones en el Perú en los últimos cien años. Estas repercusiones, sin embargo, han sido de carácter democratizador, no excluyente ni privatista, como pretende la razón tecnocrática y su inspiración neoliberal. Tampoco se refieren los impulsores de la razón tecnocrática a los intentos de «segunda reforma universitaria» que detalláramos también al inicio, en un movimiento que buscaba unir democracia con calidad en la institución universitaria. Por último, no tiene que ver tampoco con el conjunto de la ley universitaria, que tiene múltiples aspectos positivos - en cuanto a democracia interna, estructura académica, financiamiento e investigación - sino con un intento simple y llano de apropiarse del conjunto a partir del control del órgano regulador para terminar con el siglo de con- 
quistas, incompletas es cierto, que inspirara el movimiento de Córdoba. Si lo medimos entonces con las propuestas del "Manifiesto Liminar»" — corazón ideológico del movimiento cordobés- el discurso tecnocrático no busca ninguna reforma sino, más bien, una contrarreforma. En otras palabras el lobo vestido de cordero que quiere aprovecharse de los desórdenes producidos por la mediocridad.

De ahí que sería bueno, debido a la multiplicación de universidades, una distinción institucional. Subrayar el nombre «universidad» para aquellas que tienen un gobierno democrático y carecen de fines de lucro, ya «universidad» remite a una concepción universal del ser humano y por lo tanto supone una actitud para abocarse al desarrollo del conocimiento. Asimismo, agregar «particular» a aquellas instituciones que persisten en el lucro y optan por no tener un gobierno de su comunidad educativa sino tan solo de sus dueños. Estas últimas, por más esfuerzos que hagan, estarán determinadas por los intereses del dinero en su acercamiento al proceso del conocimiento, siendo particulares -al tener dueños-y no universales por definición al no estar las decisiones en manos de los agentes directos del proceso del conocimiento, ni clara su vocación de servicio a la comunidad.

Y llegamos al problema quizá si el más sensible de todos por sus repercusiones políticas: la ley señala como edad límite para el ejercicio de la docencia como profesor ordinario en las universidades públicas la edad de setenta años —elevada por el Congreso de la República en una siguiente ley a setenta y cinco años - y deja a los estatutos de cada universidad para que reglamenten el retiro. Una prueba de fuego para la pugna entre democracia, tecnocracia y mediocridad. El único Estatuto que plantea una solución es el de San Marcos. Asume el límite de la ley y señala como excepción que los docentes principales o asociados que cumplan con la edad límite, cuenten con el grado de doctor y tengan una trayectoria de investigación y publicaciones, podrán quedarse. Apunta de esta forma a dos problemas: la necesidad de re-

5 Manifiesto Liminar es el nombre que se da al Manifiesto inicial del movimiento universitario ocurrido en la Universidad Nacional de Córdoba en la Argentina, cuyo autoría fue de Deodoro Roca y que está fechado el 21 de junio de 1918. Esta pieza histórica que inicia la reforma universitaria en América Latina, resume su contenido programático y es la que abre el libro de Gabriel del Mazo (1967) sobre el tema. novación generacional de la docencia universitaria y la necesidad institucional de seguir contando con los mejores. Sin embargo, los sectores radicales se oponen a cualquier salida que no sea la ausencia del límite de edad sin los méritos respectivos. La tecnocracia en este tema, que asume especialmente caliente, prefiere mirar a otra parte. El fantasma de la mediocridad asoma detrás de este reclamo y como siempre la solución está fuera de la universidad. ¿Por qué buena parte de los docentes mayores se resisten al límite de edad para el ejercicio de la docencia? Porque no tenemos un sistema de jubilación adecuado. En cualquier sistema de jubilación, público (Oficina de Noramalización Previsional, ONP) o privado (Administradora de Fondos de Pensiones, AFP), el docente que se jubile obtendrá una suma paupérrima, en el caso de los profesores principales a tiempo completo o dedicación exclusiva entre el 10 y el 15\% de la remuneración actual que reciben. Entonces, nadie quiere irse porque supone condenarse a la pobreza. Así las cosas se trata de un problema de imposible solución, pero con un gran perjudicado inmediato: la universidad pública, que debe soportar el envejecimiento de su planta docente sin distinción alguna con muy pocos incentivos para la renovación generacional. Este es un gran desafío para la razón democrática porque hay necesidad de defender un límite de edad con la excepción respectiva y al mismo tiempo exigir un nuevo sistema de pensiones.

\section{Colofón}

¿Cuánto durará esta pugna entre democracia y tecnocracia? Es difícil saberlo. Las huestes de los primeros son solo las del saber, las de los segundos las del poder fáctico y el dinero. Pero no hay duda de que la pugna va a definir las próximas décadas de historia de la universidad. ¿Qué hay que hacer de inmediato? Potenciar un movimiento universitario de estudiantes, trabajadores y docentes que implemente la actual ley universitaria, porque ella le da a la razón democrática, por la vía de las elecciones directas de autoridades en las universidades públicas, un mayor espacio de desarrollo y la promesa, al menos, del término del cáncer de la mediocridad. Sin embargo, esta implementación, que no sabemos si será poasible, con autonomía de la Sunedu, puede permitir empe- 
zar a reconciliar democracia con calidad - el objetivo de la segunda reforma-, lo que puede llevarnos a otro estadio, fortaleciendo la razón democrática, de la situación universitaria.

En este cruce de vías nos encontramos. La razón democrática con un triunfo a medias, la mediocridad golpeada pero no desaparecida y la razón tecnocrática - con su proyecto propio- emergente y poderosa.

La mediocridad que durante décadas fue el mayor adversario de la razón democrática ahora ha devenido en obstáculo para el enfrentamiento a la razón tecnocrática. Esta última usa la mediocridad como base de apoyo para la pelea de fondo con la razón democrática que expresa un proyecto alternativo de universidad.

¿Hasta dónde irá el interés del Estado neoliberal por la universidad luego de haberla tenido abandonada tantos años? ¿Respetará la precaria democracia universitaria? ¿Le interesará el desarrollo del conocimiento más allá del cálculo fenicio de ganancias y pérdidas? Estas son las preguntas de fondo que los tiempos revueltos en los que vivimos contestarán más temprano que tarde.

\section{Bibliografía}

Degregori, Carlos Iván (1990). «La revolución de los manuales». Revista Peruana de Ciencias Sociales No.3

Del Mazo, Gabriel (1967). La reforma universitaria. Tomo I El movimiento argentino. Lima: Universidad Nacional Mayor de San Marcos.

Ley 30220 (2014). Diario Oficial El Peruano, Lima, Perú, 09 de julio de 2014. https:/www.sunedu.gob.pe/wpcontent/uploads/2017/04/Ley-universitaria-30220. pdf.

LynCH, Nicolás (1990). Los jóvenes rojos de San Marcos. El radicalismo universitario de los años setenta. Lima: El zorro de abajo ediciones.

LYNCH, Nicolás (2005). La segunda reforma universitaria. Lima: Oficina de Coordinación Universitaria/ Ministerio de Educación.

Pronabec (Programa Nacional de Becas y Crédito Educativo) (2016). Marco inicial de gasto y sus modificaciones - 2016, del mes de enero a diciembre. http:// www.pronabec.gob.pe/modTransparencia/descarga/ RepPres_2016.pdf

Salazar Bondy, Augusto (1957). Mitos, dogmas y postulados de la reforma universitaria. Lima. Facultad de Letras. Universidad Nacional Mayor de San Marcos. 